\title{
COVID-19 infection thrombosis due to hemagluttination of antibodies and COVID-19 antigens bound to erythrocytes
}

\author{
Kevin Roe ${ }^{1}$ \\ ${ }^{1}$ Retired
}

May 6, 2020

\begin{abstract}
A new pathogenic virus, COVID-19, appeared in 2019, in Wuhan, China, typically causing fever, cough, diarrhea and fatigue and significant mortality. COVID-19 has also shown about $80 \%$ genetic similarity to the Severe Acute Respiratory Symptom (SARS) virus, which is already known to be derived from a bat virus. Arterial thrombosis and venous thrombosis, variously attributed to long term patient immobilizations, inflammation, autoimmune reactions or endothelial cell damage to the blood vessels, have also been reported for COVID-19 infections. However, there is another explanation for thrombosis (blood clots) in many patients infected with COVID-19.
\end{abstract}

\section{Hosted file}

TransboundaryEmergingDiseases_LettertoEditor_bloodclotting_042920.doc available mosis-duehttps://authorea.com/users/316764/articles/447075-covid-19-infection-thrombosi
to-hemagluttination-of-antibodies-and-covid-19-antigens-bound-to-erythrocytes 